\title{
Aerobic and sequential anaerobic fermentation to produce xylitol and ethanol using non-detoxified acid pretreated corncob
}

Ke-Ke Cheng ${ }^{*}$, Jing Wu, Zhang-Nan Lin and Jian-An Zhang ${ }^{*}$

\begin{abstract}
Background: For economical bioethanol production from lignocellulosic materials, the major technical challenges to lower the production cost are as follows: (1) The microorganism should use efficiently all glucose and xylose in the lignocellulose hydrolysate. (2) The microorganism should have high tolerance to the inhibitors present in the lignocellulose hydrolysate. The aim of the present work was to combine inhibitor degradation, xylitol fermentation, and ethanol production using a single yeast strain.
\end{abstract}

Results: A new process of integrated aerobic xylitol production and anaerobic ethanol fermentation using non-detoxified acid pretreated corncob by Candida tropicalis W103 was proposed. C. tropicalis W103 is able to degrade acetate, furfural, and 5-hydromethylfurfural and metabolite xylose to xylitol under aerobic conditions, and the aerobic fermentation residue was used as the substrate for ethanol production by anaerobic simultaneous saccharification and fermentation. With 20\% substrate loading, furfural and 5-hydroxymethylfurfural were degraded totally after $60 \mathrm{~h}$ aerobic incubation. A maximal xylitol concentration of $17.1 \mathrm{gl}^{-1}$ was obtained with a yield of $0.32 \mathrm{~g} \mathrm{~g}^{-1}$ xylose. Then under anaerobic conditions with the addition of cellulase, $25.3 \mathrm{gl}^{-1}$ ethanol was produced after $72 \mathrm{~h}$ anaerobic fermentation, corresponding to $82 \%$ of the theoretical yield.

Conclusions: Xylitol and ethanol were produced in Candida tropicalis W103 using dual-phase fermentations, which comprise a changing from aerobic conditions (inhibitor degradation and xylitol production) to anaerobic simultaneous saccharification and ethanol fermentation. This is the first report of integrated xylitol and ethanol production from non-detoxified acid pretreated corncob using a single microorganism.

Keywords: Bioconversion, Corncob, Fermentation, Microbial Growth, Inhibitor

\section{Introduction}

Fuel ethanol, as a substitute for liquid petroleum fuels, is regarded as one of the important contributors to the reduction of $\mathrm{CO}_{2}$. Currently, fuel ethanol has primarily been produced using sugars from crops such as corn, sugarcane, and wheat. However, using crops for fuel ethanol production endangers the food supply, stimulating a demand for advanced technology which can produce ethanol from non-food materials such as waste agricultural and forest residues. Lignocellulosic materials comprise 30 to $45 \%$ glucan and 20 to $35 \%$ xylan, which, after pretreatment and enzymatic hydrolysis, can be converted to glucose and

\footnotetext{
* Correspondence: chengkeke@tsinghua.edu.cn; zhangja@tsinghua.edu.cn
Institute of Nuclear and New Energy Technology, Tsinghua University, Beijing * Correspondence: chengkeke@tsinghua.edu.cn; zhangja@tsinghua.edu.cn
Institute of Nuclear and New Energy Technology, Tsinghua University, Beijing 100084, P.R. China
}

xylose, respectively. The ethanol production process using lignocellulosic materials will not be economically viable if only the glucose present in the hydrolysate is converted to ethanol $[1,2]$. However, a traditionally used microorganism for ethanol fermentation, Saccharomyces cerevisiae, can only metabolite glucose to ethanol, which makes ethanol production from lignocellulosic materials lacking in competitiveness compared with that from food-based ethanol. Although recent work has succeeded in constructing an efficient xylose metabolic pathway in robust industrial Saccharomyces cerevisiae strains, the resulting strains still lacked sufficient inhibitor tolerance for efficient ethanol production using lignocellulosic hydrolysate. Many xylose-fermenting yeasts, such as Pichia stipitis, Candida shehatae, and Pachysolen tannophilus, have been investigated for their use in ethanol production 
from xylose. However, these microorganisms have much lower ethanol yields and require strict aeration conditions, which limits their use in industrial ethanol production. Some bacteria have the ability to metabolite xylose under anaerobic or aerobic conditions, converting sugars to many products in which ethanol is only a minor product [3-8]. One possibility for addressing this problem is the integrated production of other highvalue xylose-based products by means of a biorefinery. The xylan in lignocellulose can be used for high-valueadded xylitol production. Further, the glucan residue can be used to produce ethanol. With this method, the total economic viability of the integrated process is better than that with ethanol as the sole product because the price of ethanol is relatively low [1].

Lignocellulosic materials are plentiful and cheap sources of sugars. However, the conversion of cellulose to glucose is not easy, and some form of pretreatment is required. The objective of the pretreatment is to alter the structure of the lignocellulose to increase cellulose biodegradation using cellulase. Dilute acid pretreatment is a favorable route for hemicellulose hydrolysis and also improves the conversion of cellulose to glucose. This method has been successfully applied to different lignocellulosic materials for ethanol production. However, during the acid pretreatment, large amounts of various inhibitors are produced. These inhibitors mainly include furfural, 5-hydroxymethylfurfural (5-HMF), and acetic acid, and the pretreatment conditions (including temperature, time, or acid concentration) will strongly affect the dosages of these compounds and the resulting toxicity. In some previous investigations, the liquid part of the pretreated substrate was separated and then detoxified to decrease the concentration of inhibitor before the subsequent fermentation. However, detoxification usually leads to increased loss of sugar, which will decrease the product yield. Another problem during the detoxification process is the requirement for additional reagents; these reagents cannot be reused, which significantly increases the waste discharge and production cost. Thus, screening for a highly inhibitor-tolerant microorganism, which can use the hydrolysate directly to obtain desirable product, would be very attractive [9-11].

Corncob, which represents $20 \%$ of the weight of the harvested corn and has high glucan and xylan contents, is one of the most abundant lignocellulosic wastes in Northeast China. In this study, a new process of integrated aerobic xylitol production and anaerobic ethanol fermentation using non-detoxified acid pretreated corncob by Candida tropicalis W103 is proposed. The results obtained may help to find a highly effective way to produce xylitol and ethanol at the same time, which could potentially be applied in lignocellulosic ethanol production.

\section{Results}

Growth and fermentation profile of $C$. tropicalis

Candida tropicalis W103 was able to use xylose as the carbon source for cell growth and xylitol production under aerobic or anaerobic conditions (Figure 1). However, Candida tropicalis utilized xylose slowly under anaerobic conditions (Figure 1A), and only $48 \%$ of the initial xylose was consumed after $72 \mathrm{~h}$ of fermentation. The final dry cell weight (DCW) under anaerobic conditions was $0.83 \mathrm{~g} \mathrm{l}^{-1}$, much lower than the value of $4.32 \mathrm{~g} \mathrm{l}^{-1}$ under aerobic conditions. The aerobic culture also led to dramatic increases in both xylitol productivity (0.95 $\left.\mathrm{g} \mathrm{l}^{-1} \mathrm{~h}^{-1}\right)$ and yield ( $0.57 \mathrm{~g} \mathrm{~g}^{-1}$ xylose).

When glucose was used as the carbon source, ethanol was produced under aerobic or anaerobic conditions (Figure 2). C. tropicalis grew slightly slower under anaerobic conditions than under aerobic conditions. The maximum specific growth rates of $C$. tropicalis in two cases were $0.57 \pm 0.04$ and $0.53 \pm 0.05 \mathrm{~h}^{-1}$, respectively. Under aerobic conditions, only $9.2 \mathrm{~g} \mathrm{l}^{-1}$ ethanol was produced from $51.5 \mathrm{~g} \mathrm{l}^{-1}$ glucose and $1.1 \mathrm{~g} \mathrm{l}^{-1}$ glycerol was found in the broth (Figure 2B). In anaerobic conditions, a higher ethanol yield was obtained and the ethanol

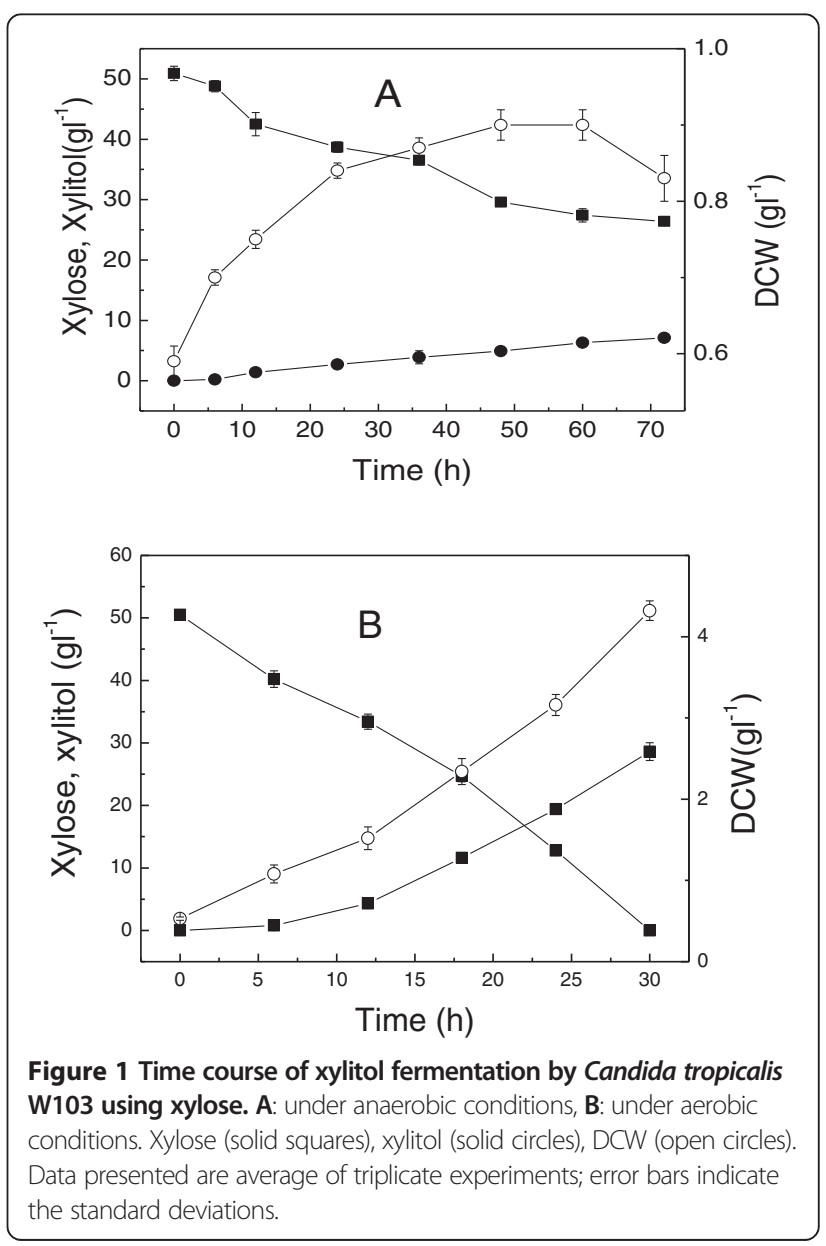




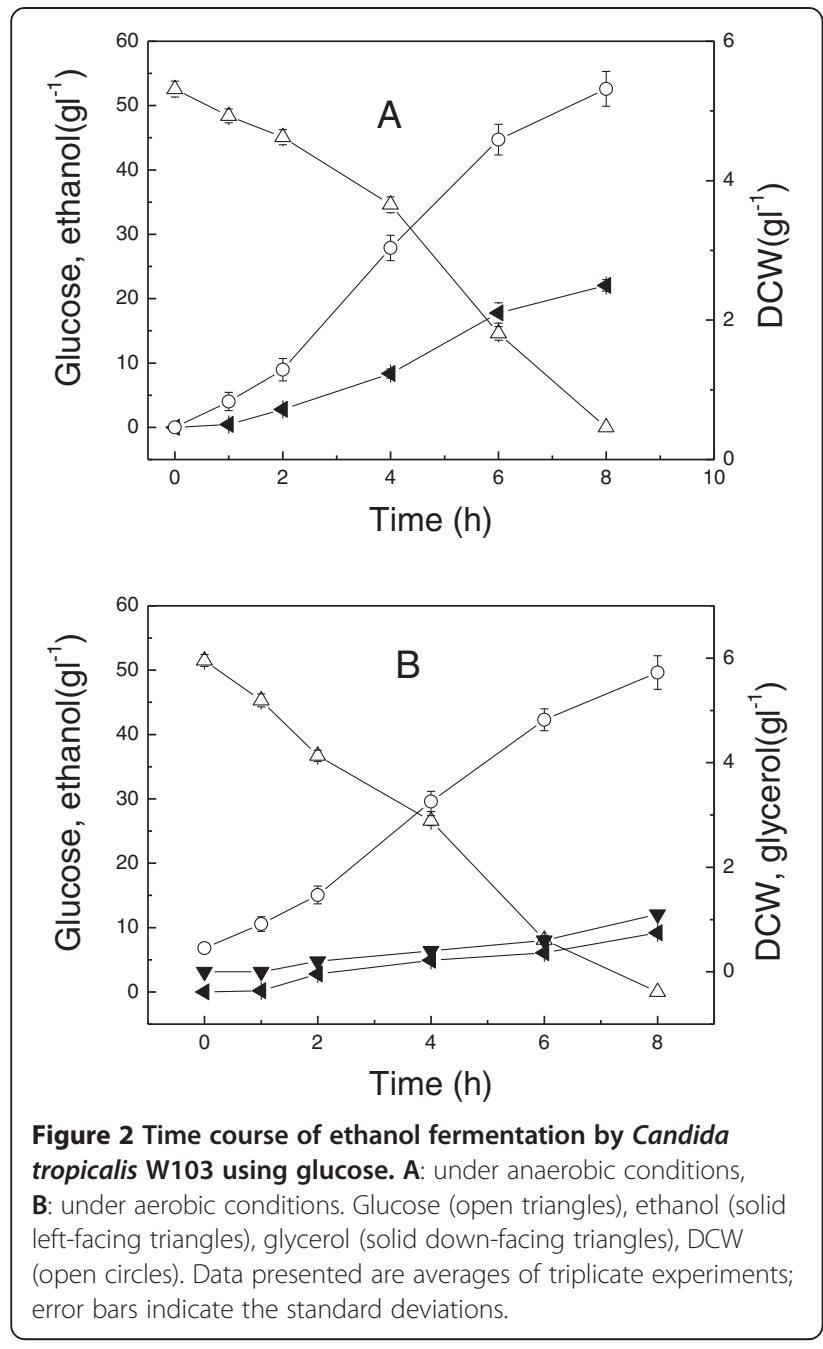

production from $52.5 \mathrm{~g} \mathrm{l}^{-1}$ glucose was $22.1 \mathrm{~g} \mathrm{l}^{-1}$, which corresponded to $82.5 \%$ of the theoretical ethanol yield. Thus, Candida tropicalis has a different capacity to metabolize glucose and xylose under aerobic or anaerobic conditions.

Considering that glucose and xylose coexist in corncob hydrolysate, C. tropicalis W103 using a xylose/glucose mixed medium was investigated under anaerobic and aerobic conditions. Under anaerobic conditions, C. tropicalis displayed sequential sugar consumption, first utilizing glucose and then xylose (Figure 3). The maximal growth rate was $0.52 \mathrm{~h}^{-1}$ in the mixture medium, similar to that of the glucose-only medium. Only ethanol formation was observed when glucose was used as the substrate. After the glucose was exhausted, about $50 \%$ of the initial xylose was consumed, and the xylitol yield was $0.29 \mathrm{~g} \mathrm{~g}^{-1}$ xylose.

Under aerobic conditions, glucose and xylose were consumed at the same time. During the glucose/xylose co-consumption stage, the consumption rate of glucose in the xylose/glucose mixed medium was $7.46 \mathrm{~g} \mathrm{l}^{-1} \mathrm{~h}^{-1}$ in 0 to $6 \mathrm{~h}$, much higher than that of xylose $\left(0.81 \mathrm{~g} \mathrm{l}^{-1} \mathrm{~h}^{-1}\right)$.
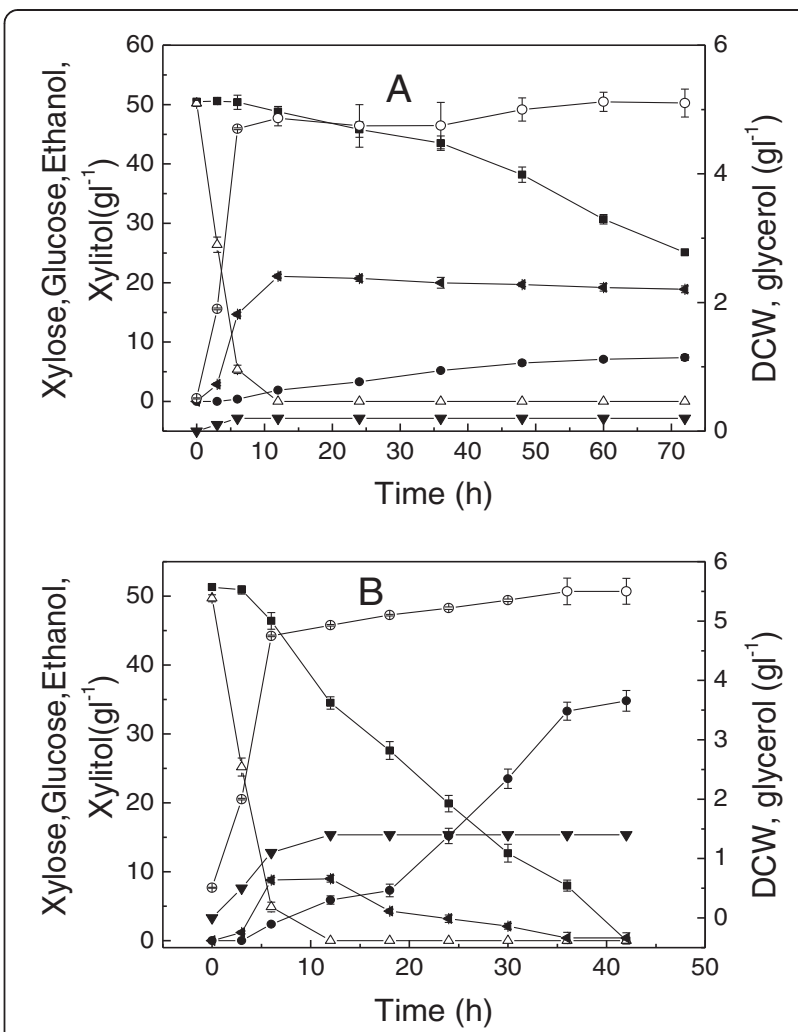

Figure 3 Sugar fermentation and cell growth of Candida tropicalis W103 using glucose and xylose mixed medium. A: under anaerobic conditions, B: under aerobic conditions. Xylose (solid squares), xylitol (solid circles), glucose (open triangles), ethanol (solid left-facing triangles), glycerol (solid down-facing triangles), DCW (open circles). Data presented are averages of triplicate experiments; error bars indicate the standard deviations.

A total of $9 \mathrm{~g} \mathrm{l}^{-1}$ ethanol and $1.4 \mathrm{~g} \mathrm{l}^{-1}$ glycerol were produced from $49.7 \mathrm{~g} \mathrm{l}^{-1}$ glucose. However, the ethanol produced in the beginning was volatilized by the end of the fermentation. The xylitol yield under the xylose/glucose mixed medium was higher than that under the xylose medium. This phenomenon can be explained by the idea that the biomass formation in a xylose/glucose mixture medium is mainly attributed to the consumption of glucose and that more xylose will be used for xylitol formation.

From the above study, we found that the xylitol fermentation should be carried out under aerobic conditions and the ethanol yield under aerobic conditions was much lower than that under anaerobic conditions. Thus, a simple aerobic or anaerobic condition is not fit for integrated xylitol and ethanol production using a xylose/glucose mixed medium. To maximize the final product concentration, an aerobic-anaerobic-combined culture was explored further. In this case, xylitol fermentation using a xylose medium (similar to the corncob xylan hydrolysate) was performed under aerobic conditions. After the xylose was consumed, a pulse addition of glucose and a shift to 
anaerobic culture for glucose fermentation (similar to the corncob glucan hydrolysate) were carried out for ethanol production.

Similar to a completely aerobic fermentation, the aerobicanaerobic-combined fermentation from 0 to $30 \mathrm{~h}$ had a good xylitol productivity of $0.96 \mathrm{~g} \mathrm{l}^{-1} \mathrm{~h}^{-1}$ (Figure 4). After shifting to anaerobic fermentation, glucose was added during 30 to $54 \mathrm{~h}$ to simulate glucose release in the enzymatic hydrolysis of glucan. In this way, the ethanol yield could still be maintained at $0.44 \mathrm{~g} \mathrm{~g}^{-1}$ glucose. The final xylitol and ethanol concentrations were 29 and $20.1 \mathrm{~g} \mathrm{l}^{-1}$, much higher than those under either completely anaerobic or aerobic conditions.

\section{Inhibitor degradation}

After acid pretreatment, the corncob hydrolysate is a xylose- and inhibitor-rich medium. The inhibitor degradation of $C$. tropicalis using a hydrolysate without detoxification, which contained $26.64 \mathrm{~g} \mathrm{l}^{-1}$ xylose, $4.34 \mathrm{~g} \mathrm{l}^{-1}$ glucose, $0.23 \mathrm{~g} \mathrm{l}^{-1}$ furfural, $0.15 \mathrm{~g} \mathrm{l}^{-1} 5$-HMF, and $1.37 \mathrm{~g} \mathrm{l}^{-1}$ acetate, was studied under anaerobic and aerobic conditions. Unfortunately, C. tropicalis had no ability to degrade the inhibitors under anaerobic conditions and neither ethanol nor xylitol was detected (data not shown). Under aerobic fermentation, low cell growth was observed, and the maximal DCW was only $1.7 \mathrm{~g} \mathrm{l}^{-1}$ (Figure 5). The maximum specific growth rate of C. tropicalis was $0.29 \mathrm{~h}^{-1}$, which was $48 \%$ lower than that in the medium using pure xylose. Furfural, 5-HMF, and acetate were triggered to degrade after glucose consumption, but prior to xylose. With non-detoxified hydrolysate as the substrate, xylitol formation was slower than that with xylose as the substrate. The final

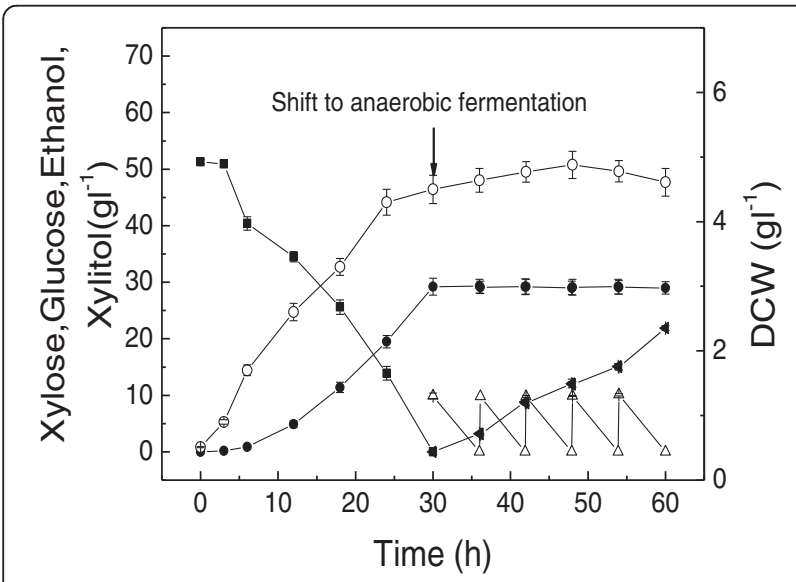

Figure 4 Anaerobic-aerobic-combined culture using Candida tropicalis W103 for xylitol and ethanol production. Xylose (solid squares), xylitol (solid circles), glucose (open triangles),ethanol (solid left-facing triangles), DCW (open circles). Data presented are averages of triplicate experiments; error bars indicate the standard deviations.
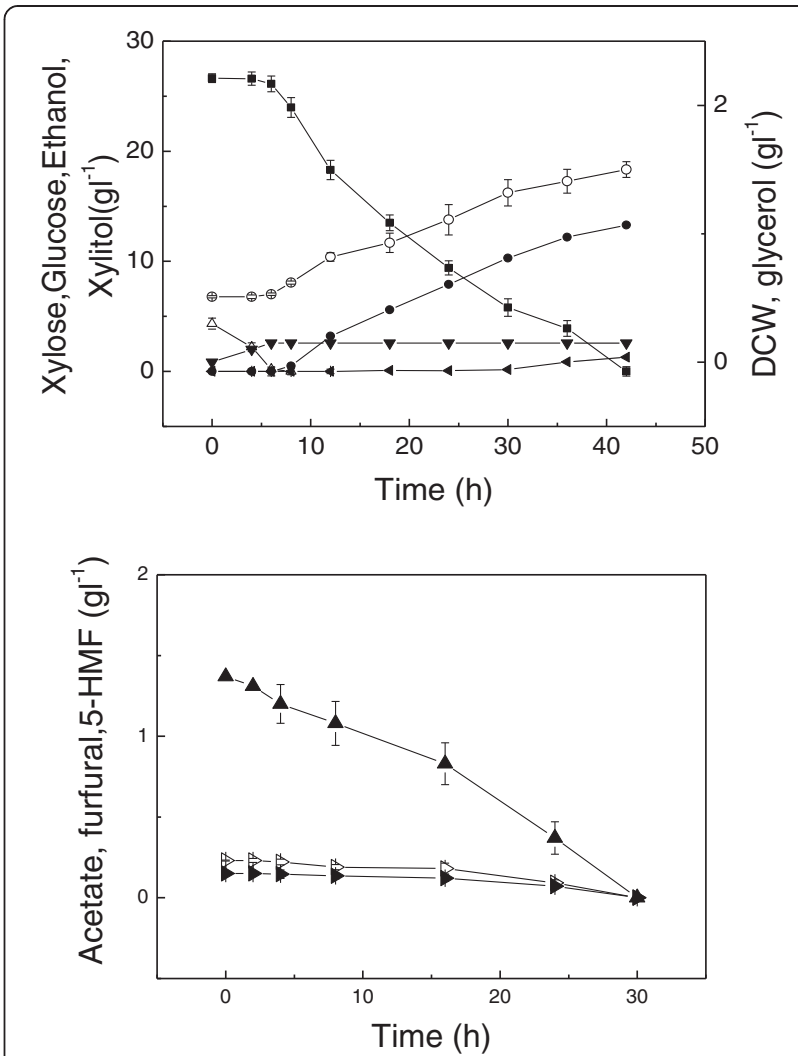

Figure 5 Inhibitor degradation of $C$. tropicalis using corncob acid hydrolysate without detoxification. Xylose (solid squares), xylitol (solid circles), glucose (open triangles), ethanol (solid left-facing triangles), glycerol (solid downward-facing triangles), DCW (open circles), acetate (solid triangles), furfural (open right-facing triangles), 5-HMF (solid right-facing triangles). Data presented are averages of triplicate experiments; error bars indicate the standard deviations.

concentration of xylitol was $13.3 \mathrm{~g} \mathrm{l}^{-1}$ with a yield of $0.5 \mathrm{~g} \mathrm{~g}^{-1}$ xylose and a productivity of $0.32 \mathrm{~g} \mathrm{l}^{-1} \mathrm{~h}^{-1}$.

\section{Combined xylitol and ethanol production}

To examine if the solids (glucan and lignin) containing hydrolysate can be used directly in xylitol and ethanol combined production, aerobic inhibitor degradation and xylitol fermentation were carried out using a pretreated corncob at a solids loading of $10 \%$. After the xylose was consumed totally, a shift to anaerobic simultaneous saccharification and ethanol fermentation was performed with cellulase addition (15 filter paper units (FPU)/g substrate). In this case $C$. tropicalis also can degrade acetate, furfural and 5-HMF, and metabolite xylose to xylitol (Figure 6). However, the rate of inhibitor degradation and xylitol production is decreased, probably due to insufficient mass transfer. Furfural and 5-HMF were degraded totally after $36 \mathrm{~h}$ aerobic incubation. A maximal xylitol concentration of $13.1 \mathrm{~g} \mathrm{l}^{-1}$ was obtained with a yield of $0.49 \mathrm{~g} \mathrm{~g}^{-1}$ xylose. Then, under anaerobic 


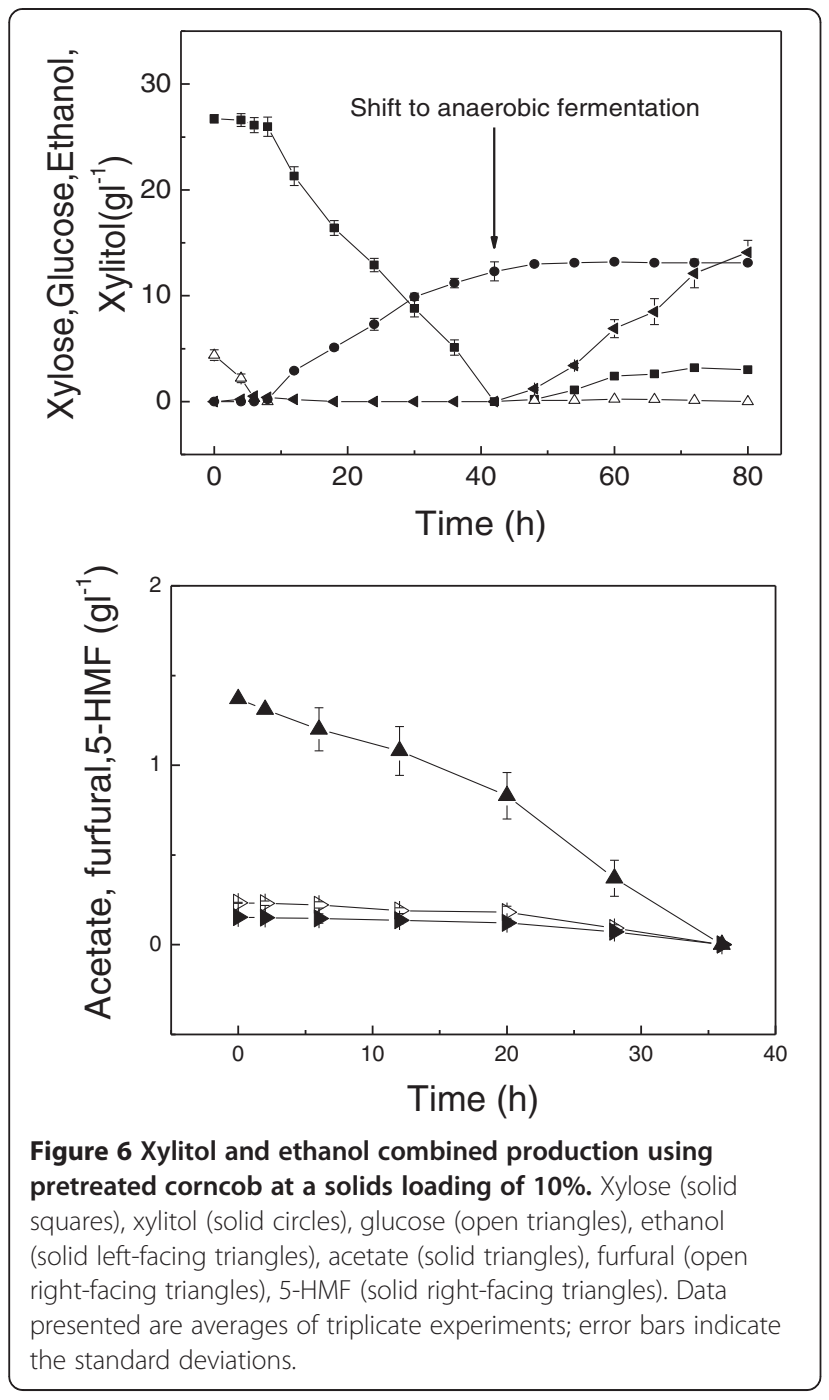

conditions with the addition of cellulase, $14.1 \mathrm{~g} \mathrm{l}^{-1}$ ethanol was produced after $48 \mathrm{~h}$ anaerobic fermentation, corresponding to $79.6 \%$ of the theoretical yield.

\section{Effect of substrate loading}

Based on the original composition of $33.2 \%$ xylan and $41.4 \%$ glucan in corncob, the theoretical yields of xylose and glucose after hydrolysis with $10 \%$ substrate loading was $37.5 \mathrm{~g}$ and $45.9 \mathrm{~g}$, respectively. However, if a higher substrate loading could be applied, it might be possible to achieve a higher sugar concentration. The initial substrate loading is very critical for xylitol and ethanol combined production from non-detoxified corncob hydrolysate because it is related to both the sugar and inhibitor concentrations.

To investigate the effect of substrate loading on xylitol and ethanol combined production, five sets of batch fermentations were carried out by adjusting strictly the initial water content to progressively increase the substrate loading. With the increase of substrate loading, the xylose and inhibitor concentrations increased. The xylitol and ethanol combined production at different substrate loadings is summarized in Table 1. Decreasing the liquid/solid ratio from 8:1 to 4:1 (based on the initial dry corncob), the xylitol yield was markedly reduced, probably due to insufficient mass transfer and higher inhibitor concentration. In this case, the concentrations of furfural and 5-HMF were $0.71 \mathrm{~g} \mathrm{l}^{-1}$ and $0.49 \mathrm{~g} \mathrm{l}^{-1}$, respectively. Only $2.3 \mathrm{~g} \mathrm{l}^{-1}$ glucose in the medium was consumed, and neither ethanol nor xylitol could be detected. Furfural and 5-HMF were not metabolized by the yeast during the fermentation process. However, the enzymatic hydrolysis seemed to be not affected by the inhibitors. At the end of the fermentation, $60.4 \mathrm{~g} \mathrm{l}^{-1}$ xylose and $61.3 \mathrm{~g} \mathrm{l}^{-1}$ glucose were found in the broth.

Figure 7 displays a typical fermentation profile of $C$. tropicalis fermenting the pretreated corncob at liquid/ solid ratio of 5:1, which caused a 12-h lag phase in aerobic xylitol production. Some inhibitors, such as furfural and 5-HMF, were metabolized totally in $60 \mathrm{~h}$. However, acetate could not be metabolized totally and was kept at a low level of $0.29 \mathrm{~g} \mathrm{l}^{-1}$ after both furfural and 5-HMF were completely degraded at $48 \mathrm{~h}$ of fermentation. The final concentration of xylitol was $17.1 \mathrm{~g} \mathrm{l}^{-1}$ with a yield of $0.32 \mathrm{~g} \mathrm{~g}^{-1}$ xylose. After $72 \mathrm{~h}$, the xylose in the broth was consumed, and the fermentation was then shifted to anaerobic culture with cellulase addition. Another $72 \mathrm{~h}$ of anaerobic simultaneous saccharification and fermentation (SSF) was carried out, resulting in the highest ethanol concentration of $25.3 \mathrm{~g} \mathrm{l}^{-1}$, corresponding to $82 \%$ of the theoretical ethanol yield.

The substrate loading of liquid/solid 5:1 resulted in the highest xylitol concentration of $17.1 \mathrm{~g} \mathrm{l}^{-1}$. However, a lower substrate concentration (liquid/solid 7:1) also gave a favorable result of $16.4 \mathrm{~g} \mathrm{l}^{-1}$ for the final xylitol concentration. The probable reasons for this were better mass transfer and lower inhibitor concentration. The highest ethanol concentration of $25.3 \mathrm{~g} \mathrm{l}^{-1}$ was obtained with a substrate loading of liquid/solid 5:1. The maximum ethanol yield from corncob was $0.155 \mathrm{~g} \mathrm{~g}^{-1}$, which was achieved at liquid/solid $8: 1$. In this process $81.5 \%$ of the glucan was hydrolyzed to monomeric glucose and then to ethanol with a yield of $0.42 \mathrm{~g} \mathrm{~g}^{-1}$ glucose.

\section{Discussion}

Many microorganisms are severely inhibited by the toxic compounds generated in the pretreatment process of lignocellulose. Thus, an efficient removal of the inhibitors is a necessary step for the bioconversion process using lignocellulosic material as the feedstock. In the previous studies on dilute acid pretreatment, efforts have been devoted to the optimization of operation parameters such as treatment temperature, time, and acid concentration to improve the yield of sugar and reduce the 
Table 1 Xylitol and ethanol combined production by Candida tropicalis W103 using pretreated corncob at different substrate loadings

\begin{tabular}{|c|c|c|c|c|c|c|c|c|c|c|c|c|c|c|}
\hline \multirow[t]{2}{*}{ Liquid/solid } & \multicolumn{5}{|c|}{ The composition before fermentation } & \multicolumn{5}{|c|}{ The composition after fermentation } & \multicolumn{2}{|c|}{ Xylitol production } & \multicolumn{2}{|c|}{ Ethanol production } \\
\hline & $\underset{\left(\mathrm{g} \mathrm{I}^{-1}\right)}{\text { Glu }}$ & $\begin{array}{c}X y l \\
\left(\mathrm{~g} \mathrm{I}^{-1}\right)\end{array}$ & $\begin{array}{l}\text { Fur } \\
\left(\mathrm{g} \mathrm{I}^{-1}\right)\end{array}$ & $\begin{array}{c}5-\mathrm{HMF} \\
\left(\mathrm{g} \mathrm{I}^{-1}\right)\end{array}$ & $\begin{array}{l}\text { Ace } \\
\left(\mathrm{g} \mathrm{I}^{-1}\right)\end{array}$ & $\begin{array}{c}\text { Glu } \\
\left(\mathrm{g} \mathrm{I}^{-1}\right)\end{array}$ & $\begin{array}{c}X y l \\
\left(\mathrm{~g} \mathrm{I}^{-1}\right)\end{array}$ & $\begin{array}{l}\text { Fur } \\
\left(\mathrm{g} \mathrm{I}^{-1}\right)\end{array}$ & $\begin{array}{l}5-\mathrm{HMF} \\
\left(\mathrm{g} \mathrm{I}^{-1}\right)\end{array}$ & $\begin{array}{l}\text { Ace } \\
\left(\mathrm{g} \mathrm{I}^{-1}\right)\end{array}$ & $\begin{array}{c}\text { Concentration } \\
\left(\mathrm{g} \mathrm{l}^{-1}\right)\end{array}$ & $\begin{array}{c}\text { Yield } \\
\left(\mathrm{g} \mathrm{g}^{-1} \text { xylose }\right)\end{array}$ & $\begin{array}{c}\text { Concentration } \\
\left(\mathrm{g} \mathrm{l}^{-1}\right)\end{array}$ & $\begin{array}{c}\text { Yield } \\
\text { ( } \mathrm{g} \mathrm{g}^{-1} \text { glucose) }\end{array}$ \\
\hline 8 & 5.43 & 33.31 & 0.18 & 0.29 & 1.71 & 0 & 3.4 & 0 & 0 & 0 & 14.7 & 0.44 & 19.7 & 0.42 \\
\hline 7 & 6.20 & 38.06 & 0.21 & 0.34 & 1.95 & 0 & 3.1 & 0 & 0 & 0 & 16.4 & 0.43 & 20.7 & 0.42 \\
\hline 6 & 7.24 & 44.41 & 0.24 & 0.39 & 2.28 & 0 & 2.8 & 0 & 0 & 0.12 & 16.0 & 0.36 & 23.2 & 0.43 \\
\hline 5 & 8.69 & 53.29 & 0.29 & 0.47 & 2.74 & 0 & 3 & 0 & 0 & 0.29 & 17.1 & 0.32 & 25.3 & 0.42 \\
\hline 4 & 10.86 & 66.61 & 0.36 & 0.59 & 3.42 & 61.2 & 66.6 & 0.59 & 0.41 & 2.70 & - & - & - & - \\
\hline
\end{tabular}

The values are the means of three independent samples.

Glu: glucose, Xyl: xylose, Fur: furfural, Ace: acetate. 


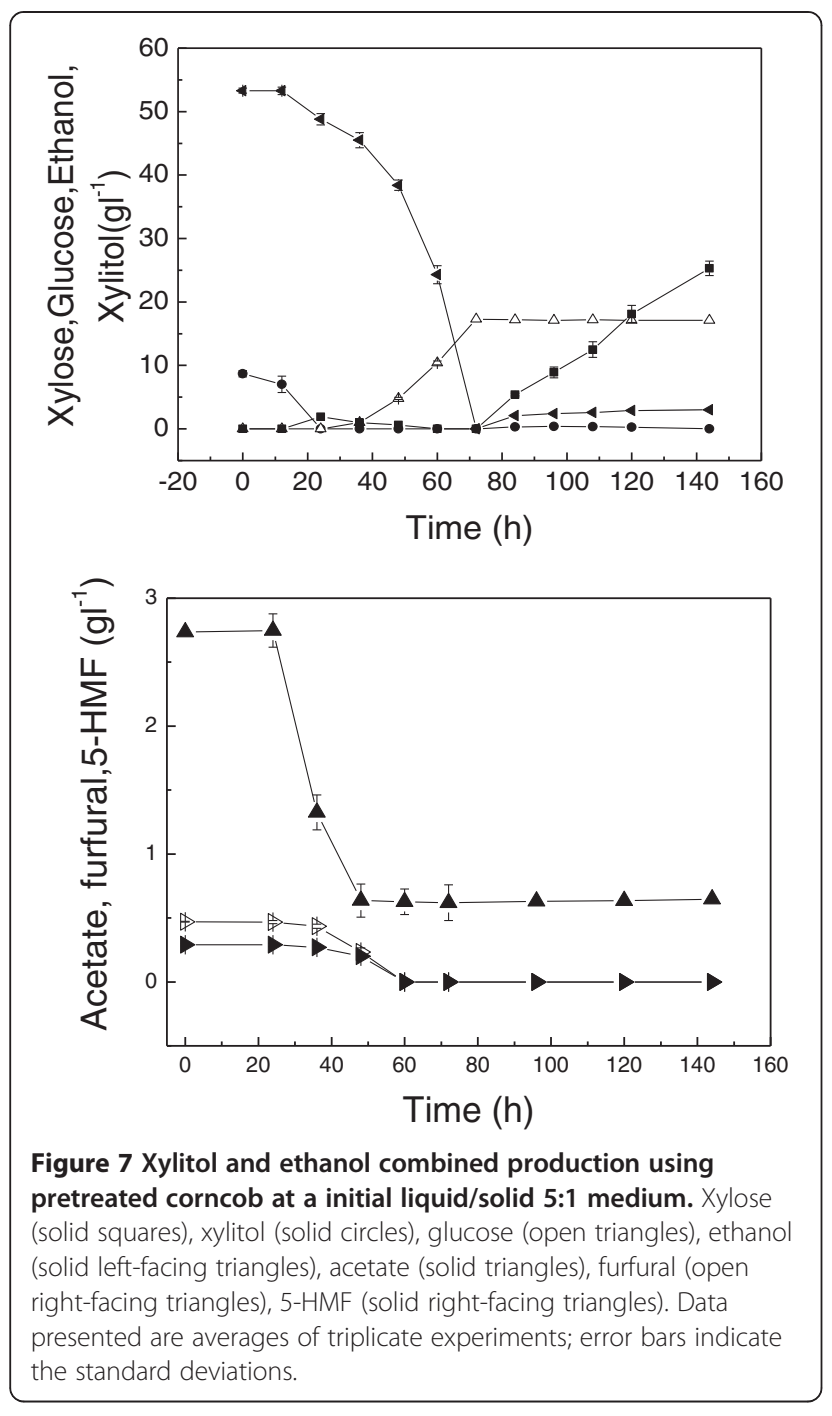

concentration of toxins by different kinds of detoxification. Many detoxification methods have been applied to alleviate the inhibition of hydrolysate for improving microbial growth. For the xylan hydrolysate part, methods such as overliming, the use of ion exchange resins, or activated charcoal adsorption can remove most of the toxins. For the solid part (mainly glucan and lignin), water washing has been used regularly in the literature. However, these methods either result in considerable loss of sugar or generate massive amounts of wastewater. Another problem during the detoxification process is the requirement for additional operation units, which significantly increases the production cost [12-15].

To avoid the drawbacks in these routine detoxification methods, the development of an inhibitor-tolerant microorganism is considered as a promising method because it has many advantages such as mild conditions, low energy input, and no wastewater release. Currently, many bacteria and fungi have been isolated and identified to have a toxin degradation capacity, but combining the inhibitor degradation with the product fermentation practice using non-detoxified lignocellulosic feedstock has not been demonstrated.

Several strains have been used to ferment xylan acid hydrolysate from various raw materials for xylitol production. Only a few studies have focused on the efficient use of all glucose and xylose in the lignocellulose hydrolysate [16-19]. In a co-culture of S. cerevisiae and Spathaspora arborariae under oxygen limitation, glucose and xylose in rice hull hydrolysate were converted to ethanol and xylitol, with concentrations of $11 \mathrm{~g} \mathrm{l}^{-1}$ and $3 \mathrm{~g} \mathrm{l}^{-1}$, respectively [20]. C. tropicalis W103 used in the present study showed good potential for xylitol and ethanol combined production because higher product concentrations and productivity were obtained. Furthermore, compared with the inhibitor concentration in the fermentation medium, C. tropicalis W103 was more tolerant to the inhibitors present in the hydrolysates.

In this study, C. tropicalis W103 is able to degrade acetate, furfural and 5-hydromethylfurfural, and metabolite xylose to xylitol under aerobic conditions and produce ethanol by SSF under anaerobic conditions. The developed yeast showed many advantages. Xylitol and ethanol combined production using C. tropicalis W103 is carried out by changing from aerobic conditions to anaerobic SSF. This process lowered the possibility of contamination by other microbial organisms because only a single inoculation was needed.

The high solids culture model was applied for inhibitor degradation by C. tropicalis W103 on the pretreated corncob directly instead of performing inhibitor degradation in the liquid hydrolysate. No cellulose degradation was observed during the C. tropicalis W103 culture on hydrolysates containing highly cellulose-rich solids, and thus the cellulose loss could be avoided in the aerobic stage. The process was also preferable because there were no additional operation units, no sugar loss, and no wastewater generation. This is particularly important because the process can combine inhibitor degradation, xylitol fermentation, and ethanol production in the same bioreactor. Finally, the high solids culture model of inhibitor degradation proved to be a fast process: most toxins were degraded within 24 to $48 \mathrm{~h}$, and the consequent xylitol and ethanol production was performed in 48 to $72 \mathrm{~h}$. Because ethanol and xylitol have different boiling points, a simple approach to remove ethanol from the fermentation broth can be carried out by evaporation, and further purification of concentrated xylitol can be done by crystallization.

The disadvantage of the current xylitol and ethanol combined production by $C$. tropicalis is its relative low product concentration compared with solo product production due to limited substrate loading. In Zhang's report, a bioreactor 
with a novel helical impeller was designed and applied to the high substrate loading. This stirring system had better performances in terms of saccharification yield, product concentration, and energy cost [21]. This new bioreactor has the potential to be applied in xylitol and ethanol combined production to obtain higher product yield and concentration.

\section{Conclusions}

In this study, a new process of integrated aerobic xylitol production and anaerobic ethanol fermentation using non-detoxified acid pretreated corncob by Candida tropicalis W103 was proposed. Its advantages include no additional operation unit, zero wastewater generation, processing on solid pretreated material, and no need for sterilization, all of which can help make the lignocellulosic ethanol industry more cost-effective and environmentally friendly, providing more potential for industrial application.

\section{Materials and methods Raw material}

The corncobs were grown in Heilongjiang Province in Northeast China and harvested in 2012. The air-dried material was ground to 2- to $4-\mathrm{mm}$ (5 to 10 mesh) particle size. The corncob particles were dried at $105^{\circ} \mathrm{C}$ for $4 \mathrm{~h}$ and then stored in sealed plastic bags at room temperature for use. The initial composition of the biomass was $2.88 \pm 0.04 \%$ benzene-ethanol extractives, $41.4 \pm 0.31 \%$ glucan, $33.2 \pm 0.41 \%$ xylan, and $18.9 \pm$ $0.33 \%$ lignin.

The cellulase used in the enzymatic hydrolysis was Cellulase 0816, which was purchased from Habio Biotech Co. Ltd. in China. The cellulase activity was determined by the method proposed by Ghose, and expressed in filter paper units (FPU) [22].

\section{Pretreatment}

The pretreatment was carried out in 500-ml glass flasks. $20 \mathrm{~g}$ of corncobs at a solid-liquid ratio of 1:3 was mixed with dilute acid $\left(0.5 \% \quad(\mathrm{w} / \mathrm{w}) \quad \mathrm{H}_{2} \mathrm{SO}_{4}+1.5 \% \quad(\mathrm{w} / \mathrm{w})\right.$ $\mathrm{H}_{3} \mathrm{PO}_{4}$ ) and pretreated in an autoclave at $130^{\circ} \mathrm{C}$ with a residence time of $60 \mathrm{~min}$.

\section{Microorganism and fermentation experiments}

Candida tropicalis W103 was grown on the preculture medium containing $10 \mathrm{~g} \mathrm{l}^{-1}$ yeast extract, $20 \mathrm{~g} \mathrm{l}^{-1}$ peptone, and $20 \mathrm{~g} \mathrm{l}^{-1}$ glucose. The seed cells were prepared in 500-ml flasks containing $100 \mathrm{ml}$ preculture medium. The flasks were incubated at $35^{\circ} \mathrm{C}$ and $180 \mathrm{rpm}$ for $14 \mathrm{~h}$ and subsequently inoculated into the fermentation medium at $10 \%(\mathrm{v} / \mathrm{v})$. The biomass concentration at the beginning of the fermentation ranged from $0.5 \mathrm{~g} \mathrm{l}^{-1}$ to $0.53 \mathrm{~g} \mathrm{l}^{-1}$.
In the growth and fermentation tests of $C$. tropicalis, the prepared xylose or glucose, supplemented with $2 \mathrm{~g} \mathrm{l}^{-1}$ $\mathrm{KH}_{2} \mathrm{PO}_{4}, 5 \mathrm{~g} \mathrm{l}^{-1}\left(\mathrm{NH}_{4}\right)_{2} \mathrm{SO}_{4}, 0.5 \mathrm{~g} \mathrm{l}^{-1} \mathrm{MgSO}_{4} \cdot 7 \mathrm{H}_{2} \mathrm{O}, 1 \mathrm{~g} \mathrm{l}^{-1}$ peptone, and $5 \mathrm{~g} \mathrm{l}^{-1}$ yeast extract, was used as the fermentation medium. All anaerobic cultures were performed as batch fermentations with 200-ml working volumes in 500$\mathrm{ml}$ pin plug flasks. The residual oxygen in the medium and head space of the flasks was not flushed out in order to support initial cell growth. The flasks were incubated at $35^{\circ} \mathrm{C}$ in an orbital shaker with a rotation speed of $100 \mathrm{rpm}$. Aerobic fermentation experiments were performed with a $100-\mathrm{ml}$ working volume in $500-\mathrm{ml}$ gauzeplugged flasks. The flasks were incubated at $35^{\circ} \mathrm{C}$ in an orbital shaker with a rotation speed of $160 \mathrm{rpm}$.

For testing the yeast's ability to degrade the inhibitors, $140 \mathrm{ml}$ of water was added to the flasks with $20 \mathrm{~g}$ pretreated corncob, and the flasks were shaken in a shaker at $30^{\circ} \mathrm{C}$ and $160 \mathrm{rpm}$ for $15 \mathrm{~min}$. The liquid fraction was recovered by filtration, and the $\mathrm{pH}$ was adjusted to 5 using $\mathrm{Ca}(\mathrm{OH})_{2}$. The obtained liquid hydrolysate, supplemented with $2 \mathrm{~g} \mathrm{l}^{-1}$ peptone and $5 \mathrm{~g} \mathrm{l}^{-1}$ yeast extract, was used as the fermentation medium.

For the xylitol and ethanol combined production, the acid-hydrolyzed corncob containing the remaining solid fraction that did not solubilize during the acid hydrolysis was used directly without sterilization. Water was added strictly to adjust the initial solid-liquid ratio of $1: 4$ to $1: 8$. The $\mathrm{pH}$ was adjusted to 5 using solid $\mathrm{Ca}(\mathrm{OH})_{2}$. The high solid medium, supplemented with $2 \mathrm{~g} \mathrm{l}^{-1}$ peptone and $5 \mathrm{~g} \mathrm{l}^{-1}$ yeast extract, was used as the fermentation medium. In the stage involving aerobic cultures for inhibitor degradation and xylitol production, these gauzeplugged flasks were incubated at $35^{\circ} \mathrm{C}$ and $160 \mathrm{rpm}$. After shifting to anaerobic simultaneous saccharification and ethanol fermentation, these flasks were sealed with pin plugs and incubated at $35^{\circ} \mathrm{C}$ and $100 \mathrm{rpm}$.

\section{Analytical methods}

The liquid samples were analyzed by HPLC (Shimadzu LC 20A, Japan), equipped with UV and refractive index (RI) detectors. The concentrations of xylose, glucose, acetic acid, glycerol, ethanol, and xylitol were determined using an Aminex HPX-87H column and an RI detector at $65^{\circ} \mathrm{C}$ with $5 \mathrm{mM} \mathrm{H}_{2} \mathrm{SO}_{4}$ as the mobile phase at $0.8 \mathrm{ml} \mathrm{min}^{-1}$. Furfural and 5-HMF were detected using a UV detector at $280 \mathrm{~nm}$. Cell growth was monitored with optical density at $650 \mathrm{~nm}$ and converted to dry cell weight (DCW) by a calibration curve.

\section{Abbreviations}

5-HMF: 5-hydroxymethylfurfural; DCW: dry cell weight; FPU: filter paper units; SSF: simultaneous saccharification and fermentation.

\section{Competing interests}

The authors declare that they have no competing interests. 


\section{Authors' contributions}

KKC participated in the design of the study, performed the experimental work, and wrote the manuscript. J-W performed the fermentation experimental work and commented on the manuscript. ZNL performed the pretreatment experimental work. JAZ participated in the design of the study and commented on the manuscript. All authors contributed to the scientific discussion throughout the work and have read and approved the final manuscript.

\section{Acknowledgements}

This study was supported by the National Basic Research Program of China (2011CB707406) and the National Natural Science Foundation of China (21176139).

Received: 22 August 2014 Accepted: 7 November 2014

Published online: 23 November 2014

\section{References}

1. Qu YB, Zhu MT, Liu K, Bao XM, Lin JQ: Studies on cellulosic ethanol production for sustainable supply of liquid fuel in China. Biotechnol J 2006, 1:1235-1240.

2. Cheng KK, Zhang JA, Erik C, Li JP: Integrated production of xylitol and ethanol using corn cob. Appl Microbiol Biotechnol 2010, 87:411-417.

3. Lin TH, Huang CF, Guo GL, Hwang WS, Huang SL: Pilot-scale ethanol production from rice straw hydrolysates using xylose-fermenting Pichia stipitis. Bioresour Technol 2012, 116:314-319.

4. Matsushika A, Inoue H, Kodaki T, Sawayama S: Ethanol production from xylose in engineered Saccharomyces cerevisiae strains: current state and perspectives. Appl Microbiol Biotechnol 2009, 84:37-53.

5. Wierckx N, Koopman F, Ruijssenaars HJ: Microbial degradation of furanic compounds: biochemistry, genetics, and impact. Appl Microbiol Biotechnol 2011, 92:1095-1105.

6. Boopathy $\mathrm{R}$, Bokang $H$, Daniels L: Biotransformation of furfural and 5-hydroxymethyl furfural by enteric bacteria. J Ind Microbiol Biotechnol 1993, 11:147-150

7. Saha B, Iten L, Cotta M, Wu V: Dilute acid pretreatment, enzymatic saccharification, and fermentation of rice hulls to ethanol. Biotechnol Progr 2005, 21:816-822.

8. Schirmer-Michel AC, Flores SH, Hertz PF, Matos GS, Zachia Ayub MA: Production of ethanol from soybean hull hydrolysate by osmotolerant Candida guilliermondii NRRL Y-2075. Bioresour Technol 2008, 99:2898-2904.

9. Schirmer-Michel AC, Flores SH, Hertz PF, Zachia Ayub MA: Effect of oxygen transfer rates on alcohols production by Candida guilliermondii cultivated on soybean hull hydrolysate. J Chem Technol Biotechnol 2009, 84:223-228.

10. Varga E, Klinke HB, Reczey K, Thomsen AB: High solid simultaneous saccharification and fermentation of wet oxidized corn stover to ethanol. Biotechnol Bioeng 2004, 88:567-574.

11. Ping $Y$, Ling HZ, Song G, Ge JP: Xylitol production from non-detoxified corncob hemicellulose acid hydrolysate by Candida tropicalis. Biochem Eng J 2013, 75:86-91.

12. Buhner J, Agblevor FA: Effect of detoxification of dilute-acid corn fiber hydrolysate on xylitol production. Appl Biochem Biotech 2004, 119:13-30.

13. Liaw WC, Chen CS, Chang WS, Chen KP: Xylitol production from rice straw hemicellulose hydrolyzate by polyacrylic hydrogel thin films with immobilized Candida subtropicalis WF79. J Biosci Bioeng 2008, 105:97-105.

14. Kiyoshi T, Jun-ichi H, Tohru K, Masayoshi K: Microbial xylitol production from corn cobs using Candida magnoliae. J Biosci Bioeng 2004, 98:228-230.

15. Villarreal MLM, Prata AMR, Felipe MGA, Almeida JBES: Detoxification procedures of eucalyptus hemicellulose hydrolysate for xylitol production by Candida guilliermondii. Enzyme MicrobTechnol 2006, 40:17-24.

16. Carvalheiro F, Duarte LC, Lopes S, Parajó JC, Pereira H, Gírio FM: Evaluation of the detoxification of brewery's spent grain hydrolysate for xylitol production by Debaryomyces hansenii CCMI 941. Process Biochem 2005, 40:1215-1223.

17. Zhang J, Zhu ZN, Wang XF, Wang N, Wang W, Bao J: Biodetoxification of toxins generated from lignocellulose pretreatment using a newly isolated fungus, Amorphotheca resinae ZN1, and the consequent ethanol fermentation. Biotechnol Biofuels 2010, 3:26.

18. Huang CF, Jiang YF, Guo GL, Hwang WS: Development of a yeast strain for xylitol production without hydrolysate detoxification as part of the integration of co-product generation within the lignocellulosic ethanol process. Bioresour Technol 2011, 102:3322-3329.

19. Almeida J, Modig T, Roder A, Liden G, Gorwa-Grauslund MF: Pichia stipitis xylose reductase helps detoxifying lignocellulosic hydrolysate by reducing 5-hydroxymethyl-furfural (HMF). Biotechnol Biofuels 2008, 1:12.

20. Hickert LR, de Souza-Cruz PB, Rosa CA, Ayub MAZ: Simultaneous saccharification and co-fermentation of un-detoxified rice hull hydrolysate by Saccharomyces cerevisiae ICV D254 and Spathaspora arborariae NRRL Y-48658 for the production of ethanol and xylitol. Bioresour Technol 2013, 143:112-116.

21. Zhang J, Chu DQ, Huang J, Yu ZC, Dai GC, Bao J: Simultaneous saccharification and ethanol fermentation at high corn stover solids loading in a helical stirring bioreactor. Biotechnol Bioeng 2010, 105:718-728.

22. Ghose TK: Measurement of cellulase activities. Pure Appl Chem 1987, 59:257-268

\section{doi:10.1186/s13068-014-0166-y}

Cite this article as: Cheng et al:: Aerobic and sequential anaerobic fermentation to produce xylitol and ethanol using non-detoxified acid pretreated corncob. Biotechnology for Biofuels 2014 7:166.

\section{Submit your next manuscript to BioMed Central and take full advantage of:}

- Convenient online submission

- Thorough peer review

- No space constraints or color figure charges

- Immediate publication on acceptance

- Inclusion in PubMed, CAS, Scopus and Google Scholar

- Research which is freely available for redistribution 